\title{
A Dimensão Simbólica da Empregabilidade: Mercado, Políticas Públicas e Organização Social do Trabalho
}

\author{
The Symbolic Dimension of Employability: Market, Public Policy and Social \\ Organization of Labor
}

\author{
Ana Heloísa da Costa Lemos \\ Doutora em Administração - IAG - PUC Rio \\ Professora do Programa de Pós-Graduação em Administração da PUC Rio \\ Rua Marquês de São Vicente 225 - Gávea - Rio de Janeiro/RJ - 22451-900 \\ aheloisa@iag.puc-rio.br \\ Alessandra Mello da Costa \\ Doutora em Administração - IAG - PUC Rio \\ Professora do Programa de Pós-Graduação em Administração da PUC Rio \\ Rua Marquês de São Vicente 225 - Gávea - Rio de Janeiro/RJ - 22451-900 \\ alessandra.costa@iag.puc-rio.br
}

\section{Resumo}

$\mathrm{O}$ artigo busca entender e contextualizar como mudanças no discurso acerca do trabalho atrelam-se a mudanças mais amplas de reorganização da produção capitalista por meio de duas premissas: 1) a atualização do papel social do mercado de trabalho é mediada por transformações que operam na esfera simbólica, criando condições que propiciam a mudança de atitude e mentalidade dos trabalhadores, adequando-os às novas condições do mercado de trabalho e, por extensão, do processo produtivo; e 2) estas transformações encontram sua forma mais acabada no discurso que se constrói em torno do neologismo empregabilidade. Os resultados nos levam a fazer ressalvas à argumentação de que o discurso sobre a empregabilidade vem propiciando a mudança de atitude e mentalidade dos trabalhadores, adequando-os às novas condições do mercado de trabalho. Apesar de estar em curso um processo de re-significação da noção de emprego e das condições de inserção no mercado de trabalho - resumidas na categoria empregabilidade - esta ainda não pode ser considerada efetiva.

Palavras-chave: Empregabilidade. Mercado de Trabalho. Políticas Públicas. Organização Social do Trabalho.

\begin{abstract}
:
This article aims to understand and contextualize how changes in the discourse about the work are linked to broader changes in the reorganization of capitalist production. The two assumptions underlying this article postulate that: 1) upgrading the social role of the labor market is mediated through transformations that operate in the symbolic sphere, creating conditions that promote change in attitude and mentality of the workers, adapting them to new labor market conditions and, by extension, of the production process and 2) changes in the order of representations associated with new organization of labor are expressed by the concept of employability. The results lead us to question the argument that the discourse on employability has facilitated the change of attitude and mentality of the workers, adapting

Artigo submetido em 30 de agosto de 2012 e aceito em 20 de dezembro de 2012 pelo Editor Marcelo Alvaro da Silva Macedo, após double blind review.
\end{abstract}


them to new conditions of the labor market. Despite being an ongoing process of redefinition of the notion of employment and conditions of participation in the labor market employability summarized in the category - this cannot yet be considered effective.

Keywords: Employability. Labor Market. Public Policy. Social Organization of Labor.

\section{Introdução}

Este artigo tem por objetivo entender como mudanças no discurso acerca do trabalho atrelam-se a mudanças mais amplas de reorganização da produção capitalista. De forma mais específica, busca-se discutir como o neologismo empregabilidade emerge como possibilidade conceitual de adequar no plano simbólico e, como decorrência, no plano objetivo, os trabalhadores a uma nova organização do trabalho.

O processo de reestruturação produtiva atualmente em curso tem provocado mudanças significativas na forma como se estrutura o mercado de trabalho, mudanças estas que têm levado a questionamentos acerca de sua capacidade de seguir sendo o principal mecanismo integrativo da sociedade (Offe, 1989). Esses questionamentos também encontram ressonância nas considerações de Harvey (2010) acerca das dificuldades que tem que ser negociadas, com sucesso, para que o sistema econômico capitalista seja viável: (a) as dificuldades provenientes das qualidades anárquicas dos mercados de fixação de preços; e (b) as dificuldades provenientes da necessidade de exercer o controle sobre o emprego da força de trabalho. No que diz respeito a essa segunda área de dificuldades, ou seja, "de conversão da capacidade de homens e mulheres de realizarem um trabalho ativo num processo produtivo cujos frutos possam ser apropriados pelos capitalistas" (Harvey, 2010, p.118), algumas premissas surgem como fundamentais, em particular a questão da disciplina ou controle da força de trabalho, que podem ser ameaçadas em um contexto marcado por transformações na esfera produtiva. Apesar do cenário de crise, no entanto, o mercado de trabalho vem sendo retratado pelo discurso dominante não como uma instituição fadada ao declínio, mas como uma criação adaptável aos novos tempos, capaz de seguir desempenhando seu papel integrador, ainda que esta integração tenda a ocorrer em novas bases (Botelho, 2009; Lemos, 2003).

No entanto, apesar de ser apregoada como uma das possíveis soluções, quando não a mais importante, para as novas configurações sócio-econômicas do mundo do trabalho contemporâneo, a temática da empregabilidade não tem merecido a devida atenção de perspectivas mais críticas. Apesar da emergência de vasta literatura acadêmica e jornalística que abordam o tema, o que pode ser identificado nos discursos é um movimento de naturalização e universalização de abordagens que apenas ressaltam os seus possíveis resultados positivos. Pouco é dito, por exemplo, sobre quais seriam os desdobramentos nas relações de trabalho contemporâneas de um conceito de empregabilidade que retrata a convergência entre os interesses das organizações e os interesses dos indivíduos que trabalham em organizações, nem tampouco questiona-se o modelo de trabalhador que o conceito de empregabilidade privilegia.

Assumindo que o discurso produz visões de mundo hegemônicas (Foucault, 2007), que enquadram, moldam e constituem as relações entre os atores sociais (muitas vezes sem aparentar isso para os próprios atores), compreender um pouco mais acerca do conceito empregabilidade adquire relevância. Neste sentido, as duas premissas que orientam este artigo postulam que: (1) a atualização do papel social do mercado de trabalho é mediada por transformações que operam na esfera simbólica, criando condições que propiciam a mudança de atitude e mentalidade dos trabalhadores, adequando-os às novas condições do mercado de trabalho e, por extensão, do processo produtivo; e (2) as transformações na ordem das 
representações encontram sua forma mais acabada no discurso que se constrói em torno da noção de empregabilidade.

Para informar o debate acerca das condições e da intensidade da adesão dos trabalhadores a uma nova lógica do trabalho por meio do conceito de empregabilidade, recorreu-se aos resultados das avaliações externas dos Planos Estaduais de Qualificação do Estado do Rio de Janeiro (PEQ-RJ), realizadas por Universidades públicas, entre os anos de 1997 e 2002. A escolha por pesquisar estes resultados do PEQ-RJ decorre: (a) dos Planos Estaduais serem parte integrante do PLANFOR; (2) das pesquisas serem concebidas e implementadas nos anos 1990, auge do contexto histórico de afirmação da nova lógica do trabalho; e (c) das pesquisas, em conjunto, serem um material sistematizado significativo, que permite ouvir um contingente expressivo de trabalhadores acerca da temática em questão.

Concebido com o objetivo de "desenvolver ações de educação profissional (...) que contribuem para reduzir o desemprego e subemprego da PEA; combater a pobreza e a desigualdade; elevar a produtividade, a qualidade e a competitividade do setor produtivo" (MTE/SPPE, 2001, p.6), o PLANFOR foi uma política pública de qualificação profissional implementada ao longo do governo Fernando Henrique Cardoso (1995-2003) que visavaarticular a formação profissional a programas de intermediação da força de trabalho, crédito popular e outros programas de geração de trabalho e renda.

A escolha desta política pública como expressão do discurso hegemônico acerca da empregabilidade deveu-se ao fato do PLANFOR representar o esforço mais persistente de qualificar a força de trabalho brasileira nos últimos quinze anos, tendo capacitado quase 15 milhões de trabalhadores brasileiros entre 1995 e 2001 (Barros, 2004; Lemos, 2003). Segundo Sousa (2007, p.257), o PLANFOR:

"espelha a concepção mais atualizada de trabalho no paradigma produtivo e tecnológico dominante, em que a necessidade de articulação ao exercício laboral tem apoio em dois argumentos: o econômico (pois a ausência ao trabalho é a causa da pobreza, esta atestada pela incapacidade de acessar as novas mercadorias produzidas) e o moral (uma vez que o distanciamento do trabalho leva à desordem social)".

Por sua abrangência, considera-se que seus efeitos simbólicos - no sentido de criar uma "nova mentalidade" - não podem ser desprezados em análises que procuram entender os condicionantes e as implicações objetivas desta mentalidade. Ao mesmo tempo, a preocupação com o aumento da empregabilidade dos trabalhadores esteve presente nos inúmeros documentos produzidos em torno do PLANFOR (Sousa, 2007). Cabe ressaltar, todavia, que o objetivo do presente estudo não foi avaliar o PLANFOR como política pública, mas utilizar os dados provenientes das avaliações sistemáticas acerca desta política como fonte de dados secundária para a análise dos eventuais efeitos simbólicos da referida política, no que diz respeito à introjeção da noção de empregabilidade.

Assim, de forma a alcançar o objetivo proposto, este artigo divide-se em cinco seções. Após esta introdução, delineia-se marco teórico que sintetiza o contexto geral de emergência do discurso sobre a empregabilidade, seguido da discussão dessa categoria a partir do conceito de poder simbólico de Bordieu (1998). A terceira seção apresenta os aspectos metodológicos do trabalho e a quarta problematiza as condições de adesão à nova lógica do trabalho, subjacente à noção de empregabilidade, no contexto da política pública vinculada pelo PEQ/PLANFOR. Na quinta - e última seção - são feitas as considerações finais.

\section{Marco Teórico}

\subsection{Reestruturação produtiva e empregabilidade}

O crescimento da competitividade decorrente do processo de internacionalização da economia tem levado as empresas a reverem suas estruturas produtivas visando a redução de 
custos e aumento da produtividade (Antunes, 2005; Alves, 2009; Botelho, 2009). Essa revisão, que ganha força a partir dos anos 1980 e consubstancia-se em discurso hegemônico nos anos 1990, implica na substituição de princípios de produção característicos do sistema taylorista/fordista, baseados na divisão de trabalho rígida, na especialização e pouca autonomia na execução das tarefas, pela multifuncionalidade e flexibilidade do trabalhador, que deve adaptar-se e oferecer respostas rápidas ao contexto em permanente mutação (Antunes, 1999).

Ainda que controversa, a superação do modelo taylorista pelo novo paradigma produtivo denominado especialização flexível vem sendo discutida desde a publicação do trabalho de Piore e Sabel (1984). A famosa tese de Braverman ([1974] 1981) sobre a polarização das ocupações - ao postular que a incorporação de tecnologia ao processo produtivo passou a requerer trabalhadores mais qualificados, por um lado, mas, por outro, levou à destituição de parte significativa da força de trabalho do controle do processo produtivo - seria o principal contraponto a noção de que a modernização produtiva requer crescentemente trabalhadores mais qualificados. Assim, a 'inexorável' modernização produtiva traduz-se na incorporação de inovações tecnológicas provenientes da informática e microeletrônica, que permite aumentar a produtividade ao mesmo tempo em que se flexibiliza o processo produtivo, reduzindo, assim, o contingente de força de trabalho necessário à produção de bens e serviços; na tendência à descentralização empresarial e industrial, como forma de possibilitar que as empresas concentrem suas atividades nas áreas em que possuem vantagens competitivas, terceirizando as que não são consideradas estratégicas; e na adoção de novos processos organizacionais tanto na produção quanto na área administrativa, visando aumentar a eficiência das organizações (Piore e Sabel, 1984; Bridges, 1995; Rifkin,1996).

Não obstante as vantagens que a reestruturação apresenta para a esfera produtiva, seus efeitos adversos podem ser percebidos no aumento dos índices de desemprego, na precarização das relações de trabalho, com o aumento do subemprego, do trabalho informal e sem direitos trabalhistas, dos contratos temporários e em tempo parcial (Castel, 1998). Cabe ressaltar que, segundo Antunes (2010, p.634), "flexibilizar a legislação do trabalho significa aumentar ainda mais os mecanismos de exploração do trabalho, destruindo direitos sociais que foram arduamente conquistados". Como chama a atenção este mesmo autor, de acordo com dados da Organização Internacional do Trabalho (OIT) cerca "de 1,5 bilhão de trabalhadores sofrerão forte erosão salarial e aumento de desemprego (...) conforme o Relatório Mundial sobre Salários 2008/2009” (Antunes, 2010, p.633).

Para o discurso econômico hegemônico, no entanto, esses são efeitos esperados e contra os quais nada se pode fazer. É o preço a se pagar por um benefício social final maior, uma vez que as soluções são centralizadas em projetos de desregulamentação por meio de privatizações, da liberalização do mercado e do sistema financeiro, da abertura das economias dos países para o mercado externo, de políticas de flexibilização laboral e de ajuste fiscal (Chomsky, 1999; Sader, 2008). Em específico com relação à questão da flexibilização laboral, Santos (2002, p.40) argumenta que:

"o consenso neoliberal é o de que o crescimento e a estabilidade econômica assentam na redução dos custos salariais, para o que é necessário liberalizar o mercado de trabalho, reduzindo os direitos laborais, proibindo a indexação dos salários aos ganhos de produtividade e os ajustamentos em relação ao custo de vida e eliminando a prazo a legislação sobre salário mínimo".

De forma complementar, Colbari (2007) mostra que o atual contexto de reestruturação das relações de trabalho é caracterizado por: (a) novos processos de socialização e qualificação para o trabalho; (b) resultados pretendidos de uma reestruturação produtiva que reduz o considerado emprego padrão (registrado, formal e protegido); e (c) um projeto político alternativo ao trabalho assalariado. Esse projeto político alternativo apresenta-se como solução para "reduzir a pobreza e resgatar a auto-estima dos desempregados, opera 
como mecanismo de preservação da integração social mediante arranjos de trabalho fora do assalariamento, como a produção familiar, a produção artesanal, a cooperativa, as variantes da economia solidária, etc" (COLBARI, 2007, p.85).

As novas formas de inserção nas atividades produtivas - como é o caso do conceito de empregabilidade - convergem para o que Boltanski e Chiapello (2009, p.58) destacam como sendo uma importante característica do capitalismo atual: pode-se identificar as mudanças ideológicas que acompanharam as transformações do capitalismo nos dias de hoje com o objetivo de justificar o engajamento necessário - em especial em um modelo de capitalismo considerado significativamente custoso em termos humanos - para o funcionamento do sistema como um todo:

"O capitalismo, sob muitos aspectos, é um sistema absurdo: os assalariados perderam a propriedade do resultado de seu trabalho e a possibilidade de levar uma vida ativa fora da subordinação. Quanto aos capitalistas, estão presos a um processo infindável e insaciável, totalmente abstrato e dissociado da satisfação de necessidades de consumo, mesmo que supérfluas. Para esses dois tipos de protagonistas, a inserção no processo capitalista carece de justificações" (Boltanski e Chiapello, 2009, p.38).

No que diz respeito às especificidades do caso nacional, o agravamento do quadro de desemprego no país não por acaso coincidiu com a hegemonia do liberalismo e do monetarismo como doutrinas econômicas nos governos Fernando Collor e Fernando Henrique Cardoso nos anos 1990 (Alves, 2009; Cardoso, 2000). Esta combinação pautou o debate público sobre o desemprego, a partir de um enfoque que privilegia a dimensão individual do problema - expresso pela categoria empregabilidade - ao invés de apresentar respostas de corte keynesiano, que pressupõe o desenvolvimento de políticas fiscais ativas, comprometidas com a criação de empregos. Nunca é demais lembrar que nos quarenta anos posteriores à crise de 29, as idéias de Keynes orientaram as discussões dos economistas sobre as políticas de emprego a serem adotadas tanto nos países centrais quanto nos periféricos.

Em outros termos, até a década de 70 o desemprego era um problema a ser enfrentado através de políticas públicas capazes de criar empregos. Mas a crise do welfare state europeu que começou a dar sinais na década de 70 e a ascensão de governos de orientação liberal como resposta à referida crise - eclipsaram as propostas de Lord Keynes.

Neste sentido, sob a influência das transformações no debate internacional sobre o desemprego, parte expressiva dos economistas nacionais (Barros, 2001; Soares e Gonzaga, 1997; Ramos e Reis, 1997; Alves e Vieira, 1997; Amadeo, 1998; Neri, Camargo e Reis, 1999), alguns dos quais antigos defensores de Keynes, como Amadeo (1987), começaram a sugerir respostas para a crise que passam ao largo de políticas de orientação keynesiana, consideradas inadequadas aos "novos tempos". Suas análises, ancoradas em pressupostos da teoria do capital humano de Schultz (1967) - que concebe os investimentos em educação como meio de aumentar a qualidade e a produtividade da força de trabalho e alavancar o crescimento econômico - corroboram a tese de que a crise de desemprego contemporânea requer substanciais investimentos em formação profissional. Estes investimentos seriam os principais recursos para garantir o aumento da produtividade e, conseqüentemente, da empregabilidade da força de trabalho brasileira.

Apesar de não ser a única proposta em debate, - economistas como Pochmann (2001a, 2001b), Baltar e Matoso (1997), Coutinho (1997) argumentam que a raiz da crise atual de desemprego está na inserção subordinada do Brasil na divisão internacional do trabalho, portanto, somente a revisão dos termos dessa divisão poderia amenizar a crise - a valorização de ações voltadas para a qualificação da força de trabalho, como forma de possibilitar aos trabalhadores a conquista de empregos, surge como ponto de convergência entre empresariado, governo e trabalhadores. A questão da formação profissional é retratada como o grande desafio a ser enfrentado pela sociedade (Alencar e Granemann, 2009). A possibilidade de acordo em torno da questão da qualificação profissional - acordo parcial, é 
verdade, pois não há um consenso claro sobre a forma de se lidar com o problema - faz com que as atenções de diferentes atores se voltem para esta alternativa. Se não há um entendimento quanto à forma de melhorar a qualificação dos trabalhadores, há pelo menos um acordo de que algo precisa ser feito no que tange à capacitação, de que a força de trabalho brasileira é mal-preparada. É nesse contexto de valorização da necessidade de qualificação profissional que surge o termo empregabilidade.

Entendida como elegibilidade para o emprego; condição de ser e manter-se empregável (Cardoso et alli, 1997) a empregabilidade torna-se a depositária das esperanças dos trabalhadores na conquista do tão sonhado emprego, ao mesmo tempo em que se converte em explicação (e saída) para o problema do desemprego no país: este só é elevado porque os trabalhadores são pouco empregáveis mas, uma vez suprida esta deficiência, o problema - diz o discurso dominante - tenderá a arrefecer.

\subsection{O discurso sobre a empregabilidade}

Definida como condição de ser empregável, isto é, de dar ou conseguir emprego para os conhecimentos, habilidades e atitudes intencionalmente desenvolvidas por meio de educação e treinamento sintonizado com o mercado de trabalho (Rodrigues, 1997; Teixeira e Rios, 1998; Machado, 1998), a empregabilidade tem como seus principais porta-vozes consultores de empresas, empresários, profissionais de recursos humanos e economistas de orientação liberal. Conforme foi anteriormente dito, são estes últimos que nos seus inúmeros artigos acadêmicos trazem os alertas e dados sobre a baixa qualificação da força de trabalho, a pouca escolaridade (quando comparada a de outros países) dos brasileiros, além de chamarem atenção para o fato do aumento da competitividade da indústria nacional, baseada na incorporação de inovações tecnológicas ao processo produtivo, requerer mão-de-obra capacitada a operar os novos equipamentos. Em outras palavras, afirmam que a baixa qualidade da força de trabalho pode comprometer o crescimento econômico do país, contribuindo para a retomada e atualização da teoria do capital humano. Afirmam, também, que os trabalhadores que lograrem aumentar sua escolaridade e capacitação técnica conseguirão se inserir no mercado de trabalho, pois há vagas não ocupadas em decorrência da baixa qualificação da força de trabalho.

Se os economistas são os principais responsáveis pelo discurso técnico sobre a empregabilidade, a popularização do termo dá-se, no entanto, através da mídia impressa e eletrônica. Jornais de grande circulação, revistas semanais (Veja, Época, Exame, Isto é, Você S.A., para citar as mais populares), programas (Globo Repóter) e noticiários de televisão encarregam-se de fazer chegar a todos a necessidade do aumento da qualificação profissional para garantir a entrada e permanência no mercado de trabalho. Mesmo quando o termo empregabilidade não é utilizado, a idéia que lhe é subjacente é fartamente divulgada. Essa mídia de massa articula e difunde uma visão de mundo particular, edificando idéias, comportamentos, projetos políticos e econômicos, contribuindo para a homogeneização dos conceitos e práticas administrativas. Apresenta-se, portanto, como um importante veículo para a disseminação de ideologias na sociedade em função da abrangência de seu poder de comunicação e pela sua capacidade de difundir idéias. Assim, alimenta um imaginário social específico (Wood Jr e Paula, 2006) e efetiva-se por meio de um processo de: (a) promoção de valores associados ao sucesso profissional; (b) indução pelo poder da influência e do prestígio de agendas específicas junto ao público executivo; (c) divulgação sistemática de novidades gerenciais; e (d) legitimação das novidades gerenciais (Wood Jr e Paula, 2001).

Quando se tratam de publicações destinadas aos profissionais com maior qualificação - como as revistas Exame e Você S.A., por exemplo - o assunto é mais enfatizado, reforçando junto a seus leitores a importância de estarem permanentemente preocupados com a questão. Nas reportagens e artigos que povoam esses periódicos é clara a mensagem de que o Lemos, A. H. C.; Costa, A. M. 
profissional deve estar atento às necessidades do mercado e que a conquista da empregabilidade é uma questão preponderantemente individual.

Para os profissionais com baixa ou nenhuma escolaridade preconiza-se, antes de mais nada, o aumento dessa qualificação. Para estes, educação básica é apresentada como o principal requisito de empregabilidade. Ao lado da valorização da escolaridade, competência, flexibilidade, motivação, capacidade de aprendizagem e bom convívio social aparecem como complementos que conformam o perfil do empregável. Melhor preparados, os profissionais de nível médio e superior, encontram mais desafios e são exigidos em mais requisitos que incluem não só os citados anteriormente, mas ainda itens como múltiplos conhecimentos e habilidades, capacidade de trabalho em equipe, domínio de microinformática, atualização profissional permanente, dentre outros. O que se observa é que quanto maior o nível de escolaridade do profissional, maiores são os requisitos que garantem sua empregabilidade podendo, no caso de gerentes, executivos e outros profissionais de nível superior incluir itens como sólida formação acadêmica (pós-graduação, MBA e mestrado desejáveis), domínio de idiomas estrangeiros, capacidade de fazer seu marketing profissional, capacidade de liderar, criação de uma vasta rede de relações pessoais e profissionais, iniciativa e capacidade de assumir riscos.

O que o discurso sobre a empregabilidade não explica são os motivos pelos quais, não obstante o principal fator de empregabilidade ser a educação formal e profissional - este é o principal ponto na argumentação dos economistas - nem os trabalhadores com elevada formação escolar estão livres da ameaça constante do desemprego (se para os pouco qualificados o estudo é tudo, para os instruídos o estudo não basta). Assim, competência e empregabilidade, as duas pedras-de-toque do discurso, são termos específicos o suficiente para serem invocados pelos eleitos pelo mercado de trabalho - legitimando seu ingresso e permanência neste - e para servirem de receituário a ser recomendado aos que desejam fazer parte do seleto grupo de profissionais "competentes"; ao mesmo tempo, são conceitos vagos o bastante para taxar todos os fracassados na disputa como incompetentes ou "inempregáveis", pois sempre haverá alguma coisa que lhes faltou; alguma habilidade que não foi suficientemente desenvolvida; sempre haverá um motivo para justificar a exclusão daqueles que, da suposta disputa meritocrática por postos de trabalho, só guardam o sabor amargo da derrota.

Todavia, apesar do predomínio da literatura que reforça o sentido positivo do conceito de empregabilidade, fazendo do termo quase uma palavra de ordem para os trabalhadores contemporâneos, não se pode deixar de mencionar alguns trabalhos nacionais recentes que discutem o tema, a partir de uma perspectiva crítica. A percepção de que a noção de empregabilidade surge como um recurso discursivo capaz de reforçar a ideia de que o trabalhador é o único responsável pela sua inserção no mercado de trabalho é destacada tanto por Carrieri e Sarsur (2004), que consideram o termo como uma estratégia da alta administração das empresas para responsabilizar o trabalhador pela não contratação ou demissão, quanto no trabalho de Lemos, Rodriguez e Monteiro (2011) que discute o tema, tendo como base conceitos apresentados por Foucault em alguns de seus textos clássicos, sobretudo em Vigiar e Punir. Os referidos autores conduzem uma reflexão crítica que aborda as dimensões subjacentes à categoria empregabilidade menos como garantidoras de autonomia individual e mais como perpetuadoras da submissão dos trabalhadores à dinâmica do sistema produtivo. Somam-se a esses trabalhos a análise de Sarsur (2001) que contrapõe os conceitos de empregabilidade e "empresabilidade", desmistificando-os, o artigo de Náder e Oliveira (2007) que ressalta que as chances de colocação de um trabalhador são dependentes não somente de suas estratégias e características individuais, mas também das condições do mercado de trabalho e a pesquisa de Helal e Rocha (2011) que compara textos produzidos na academia e no mundo empresarial. Finalmente, ao lado desses estudos mais críticos, deve-se 
mencionar ainda os trabalhos de Helal, Neves e Fernandes (2007) sobre a empregabilidade gerencial no Brasil, o de Lemos e Pinto (2008) acerca da empregabilidade dos administradores, bem como o de Lopes e Silva (2009) sobre a inserção no mercado de trabalho de profissionais de TI, como forma de ilustrar o interesse que a temática empregabilidade vem despertando na academia brasileira, na última década.

\subsection{A dimensão simbólica da Empregabilidade}

A ênfase na necessidade de qualificação dos trabalhadores, presente no discurso sobre a empregabilidade, deve-se, em parte à sua dimensão objetiva, pois o processo produtivo moderno necessita, efetivamente, de mão-de-obra qualificada para expandir-se e realizar os ganhos de produtividade que o uso da tecnologia pode propiciar, ainda que esta necessidade não seja tão ampla quanto parece, pois, ao lado dos postos que exigem maior qualificação, subsistem outros que, justamente por sua natureza automatizada, não requerem nada além da capacidade de ler instruções simples e manipular botões ou alavancas, conforme já havia ressaltado Braverman ([1974]1981) e é confirmado por Pochmann (2001a), em análise acerca do caso brasileiro.

Parte da ênfase - talvez a mais significativa - deve-se, no entanto, à sua dimensão simbólica. Nesta dimensão, o discurso sobre a empregabilidade opera como forma de garantir a submissão de parte significativa da força de trabalho ao processo produtivo, ainda que essa ligação seja, para muitos, apenas potencial - enquanto o trabalhador acredita que é possível conseguir um emprego ele se coloca à disposição do mercado de trabalho, se disciplina por suas regras e se sujeita às privações da falta do emprego porque crê ser uma situação provisória, além de vivenciar essa falta de trabalho como uma deficiência individual. É essa segunda dimensão que é o foco deste artigo, pois os efeitos concretos desse discurso não se limitam a assegurar a busca de melhores qualificações pelos trabalhadores, mas garantem ao mercado de trabalho sua condição de principal mecanismo integrativo da sociedade, ainda que a integração objetiva - via oferta de postos de trabalho - por este propiciada se torne cada vez mais precária e menos estável e abrangente.

Cabe ressaltar que várias podem ser as possibilidades de estudo acerca dos aspectos simbólicos envolvendo as relações de trabalho. Apenas como exemplo de pesquisadores brasileiros, podemos destacar: (1) a coletânea de artigos de Carrieri e Saraiva (2007) e o artigo de Wood Jr (2000) acerca do simbolismo organizacional; (2) os artigos de Saraiva et al (2011) e Rosa e Mozar (2009) acerca dos significados do trabalho para os trabalhadores; e (3) os trabalhos que pesquisam a relação entre os aspectos simbólicos e a cultura organizacional, como a coletânea de artigos coordenada por Carrieri, Cavedon e Silva (2008). No caso do presente trabalho, assume-se a premissa de que a forma como se constitui e se apresenta o discurso sobre a empregabilidade permite discutir esta construção nos marcos do conceito de poder simbólico, como concebido por Pierre Bourdieu (1998).

Conceito central na obra deste autor, este faz referência à construção de sistemas simbólicos que atuam como instrumentos de integração social e, por seu intermédio, estabelecem o consenso acerca do entendimento do que é o mundo. Este poder, ao mesmo tempo em que se origina nas relações de força presentes na esfera da produção, funciona como reforço dessas relações, na medida em que as reproduz de forma velada (seu caráter simbólico).

Ainda segundo o autor, o poder simbólico diz respeito à capacidade do grupo dominante no campo da produção de impor como verdadeira, natural, sua visão de mundo particular. Ou seja, para Bourdieu (1998) o campo de produção simbólica é um espaço de luta no seio do qual as diferentes classes travam uma batalha com o intuito de apresentar a sua definição do mundo social como predominante. E esta imposição é tanto mais poderosa na medida em que não aparece como tal: o caráter coercitivo da inculcação de uma determinada Lemos, A. H. C.; Costa, A. M. 
forma de ver o mundo desaparece ao mesmo tempo que esta versão perde seu caráter particular e se torna a única versão sobre o mundo (ou ao menos a dominante; a oficial). E é exatamente a imposição de uma forma particular de ver o mundo constitui-se em processo de violência simbólica. Para Bourdieu (1998), seu caráter velado não minimiza a violência subjacente ao processo de fazer ver e fazer crer o que convém àqueles que se encontram em posição dominante no campo da produção de bens econômicos e simbólicos: o poder simbólico é uma forma transfigurada de outras formas de poder, transfiguração esta que torna invisíveis as relações de força que lhe são subjacentes e que faz perpetuar.

Partindo-se da constatação da existência desses sistemas pode-se conceber a construção do conceito de empregabilidade como elemento importante para a forma como ocorre, nos dias de hoje, a integração da sociedade. Isto é, enquanto representação simbólica, opera no sentido de criar novos valores e representações, condizentes com o mercado que se transforma, capazes de ajustar as expectativas das classes dominantes, da classe trabalhadora e do governo às novas realidades do mundo do trabalho.

Baseado nessa concepção pode-se perceber o discurso sobre a empregabilidade como a forma de imposição da visão sobre a crise do mundo do trabalho conveniente às classes dominantes no campo econômico. Esta visão tem a peculiaridade de transferir para os trabalhadores - dominados no campo da produção - os ônus da reestruturação produtiva, na medida em que são eles que devem criar as condições que permitam sua entrada e permanência no mercado. A hipótese do mercado de trabalho ser reformulado, com vistas a prever formas de integração capazes de incorporar os contingentes de trabalhadores que se tornam excedentes, problema central na esfera produtiva, fica em segundo plano, bem como as propostas que pressupõem a ação do Estado como promotor de políticas capazes de incrementar a criação de empregos.

Desta forma, por meio do que Bourdieu denomina efeito conhecimento/desconhecimento, o problema que se constrói, que se faz conhecer - a necessidade dos trabalhadores se tornarem empregáveis - serve também para obscurecer dois problemas cujo debate não convém às classes dominantes: (a) a insuficiência crescente do mercado de trabalho enquanto mecanismo alocativo da força de trabalho disponível na sociedade; e (b) o a perda de referentes coletivos que, segundo Alves (2009, p.190), consubstancia-se no desmonte do sindicalismo do confronto e desdobra-se em modificações nas condições de luta sindical e política dos trabalhadores "como as negociações coletivas segmentadas e a fragmentação do estatuto salarial".

\section{Aspectos metodológicos}

A pesquisa utilizou como fonte de dados secundários os relatórios gerenciais de avaliação dos PEQs, produzidos no âmbito do PLANFOR. Estes relatórios consolidam as avaliações dos PEQs do Rio de Janeiro realizadas pela UNITRABALHO em 1997, 1998, 1999 e 2000 e pelo FUJB/LABTEC/UFRJ em 2001 e 2002. Com o intuito de avaliar a intensidade da adesão (ou da não adesão) dos beneficiários da política de qualificação profissional à noção de empregabilidade procurou-se interpretar os resultados dessas avaliações buscando verificar até que ponto os trabalhadores vêm efetivamente introjetando este conceito, construído ao longo das últimas décadas, e adequando-se às novas condições do mercado de trabalho. Os relatórios consultados consolidam resultados de levantamentos feitos juntos aos egressos dos PEQs, com vistas a avaliar a eficiência e eficácia da política pública. Os aspectos mensurados incluem: inserção no mercado de trabalho, manutenção do trabalho, elevação da renda e percepção dos egressos acerca da importância do curso atendido para sua vida laboral. Os dados foram analisados por meio de estatística descritiva. A pesquisa avalia tanto as condições de inserção no mercado de trabalho dos indivíduos que lograram obter uma A Dimensão Simbólica da Empregabilidade: Mercado, Políticas Públicas e Organização Social do Trabalho 
ocupação, após a participação no programa, quanto aqueles que continuaram desocupados ou mesmo vieram a perder o emprego, após a conclusão do curso.

Para a presente pesquisa, dentre os vários resultados componentes dos relatórios de avaliação, aqueles que buscavam perscrutar a percepção dos egressos desempregados quanto à qualidade e relevância do treinamento recebido foram considerados particularmente significativos para se avaliar o impacto subjetivo da política pública junto a seu público-alvo. Apesar de impactos subjetivos não serem da fácil mensuração, entendeu-se que o contraste entre os dados de inserção efetiva do egresso no mercado de trabalho e os dados que indicam a importância que este atribui ao curso forneceriam uma informação que permitiria avaliar se o egresso, não obstante seguir desempregado após o processo de qualificação (curso), considerou relevante sua participação no programa de qualificação. As avaliações positivas dos cursos do PEQ/PLANFOR pelos egressos, nos casos em que estes não lograram obter emprego, foram interpretadas como indício de adesão subjetiva destes egressos à uma nova lógica do trabalho. Os resultados dessa análise são apresentados no tópico seguinte.

\section{Análise dos resultados: o PLANFOR e a inculcação da luta pela empregabilidade}

Conforme anteriormente destacado, este item analisa os resultados dos PEQs que indicam as avaliações feitas pelos egressos que continuaram desempregados (ou perderam seus empregos), após a conclusão dos cursos. Estes resultados foram considerados particularmente interessantes face ao propósito de explorar os impactos subjetivos dos cursos sobre os egressos. Em outros termos, interessou saber se, não obstante mal-sucedido na procura por uma ocupação, o egresso do PEQ avaliou positivamente a formação recebida, contribuindo, assim, para a legitimação da política pública. Este resultado, juntamente com aqueles que apontam os fatores relacionados pelos egressos como responsáveis por seu desemprego, foram interpretados à luz da indagação quanto ao grau de adesão dos egressos aos pressupostos inscritos no PLANFOR.

\subsection{Benefícios atribuídos aos cursos pelos egressos que continuaram desempregados}

Quando perguntados sobre os benefícios advindos da participação nos cursos, os egressos que continuaram desocupados na ocasião da AVAL de 1997 apresentam uma avaliação positiva do mesmo, pois:

"24,7\% das respostas indicaram o aumento das chances de conseguir trabalho; $22,5 \%$ das respostas afirmam que os egressos sentem-se mais habilitados para conseguir trabalho na área do Curso; e 16,11\% sabem que agora precisam estar mais atualizados. Apenas 10,87\% das respostas sinalizaram que o Curso não trouxe nenhum benefício para os egressos" (UNITRABALHO, 1997:54).

O que chama atenção nesses resultados é o fato de um grupo significativo de egressos (superior a 50\%), não obstante continuar desempregado, avaliar positivamente os efeitos dos cursos na sua vida profissional. Pode-se dizer que a empregabilidade percebida destes egressos aumentou, apesar destes não terem logrado obter trabalho. Os egressos que permaneceram desocupados após a realização do PEQ de 1998 também apontam na direção do aumento da empregabilidade percebida, pois os entrevistados afirmam que:

"adquiriram mais conhecimentos (30\%), acreditam ter aumentado as chances de conseguir trabalho (20,9\%), sentem-se mais habilitados para conseguir trabalho na área do curso $(17,2 \%)$, compreenderam a necessidade de estarem atualizados (13,2\%)" (UNITRABALHO, 1998:197).

Mais adiante no Relatório esta percepção confirma-se uma vez que:

"Respondendo à pergunta se o curso havia atendido às suas expectativas, 61,8\% dos egressos afirmaram que sim, $32,5 \%$ em parte, e apenas $5,7 \%$ disseram que não. O significado desses resultados pode indicar que, mesmo não atingindo plenamente seu objetivo imediato - um emprego ou trabalho - os cursos atendem a outras aspirações, como as evidenciadas na questão

Lemos, A. H. C.; Costa, A. M. 
sobre os efeitos do curso na vida pessoal: $29,9 \%$ afirmaram ter adquirido mais conhecimentos; $15 \%$ desenvolveram a auto-estima, aumentando a confiança em si próprios; $12 \%$ afirmam que agora possuem maior capacidade de pensar, permitindo compreender a realidade de uma forma que não era acessível antes. Nesse sentido, a quase totalidade dos egressos recomendariam o curso para outras pessoas $(97,2 \%)$, conferindo, em escala de 1 a 5 , a nota média 4 ao curso freqüentado. Ainda nessa seqüência, como resultado da avaliação positiva, $70,5 \%$ procuraram e realizaram outros cursos de qualificação profissional, enquanto apenas $29,5 \%$ cursaram apenas um”. (UNITRABALHO, 1998: 203).

É interessante observar o elevado percentual de egressos que afirmam que o curso "atendeu a seus objetivos" (61,8\%), não obstante terem permanecidos desempregados. Esta resposta, além de revelar a aprovação do curso pelo egresso, pode ser interpretada como indicativa da valorização da noção de empregabilidade. $O$ fato dos entrevistados recomendarem o curso a outros $(97,2 \%)$, bem como revelarem interesse em participar de outros programas $(70,5 \%)$ sugerem a valorização da qualificação profissional como um valor em si, independente dos efeitos "práticos" da formação recebida.

A avaliação positiva dos efeitos dos cursos entre os desocupados também se repete no ano seguinte. Na AVAL de 1999 os principais benefícios apontados pelos egressos sem trabalho foram:

"adquiriram mais conhecimentos $(11,97 \%)$, acreditam ter aumentado as chances de conseguir trabalho $(54,42 \%)$, e sentem-se mais habilitados para conseguir trabalho na área do curso (14,53\%)" (UNITRABALHO, 1999:57).

Novamente o insucesso na procura por uma ocupação não levou os egressos a reprovarem a política de qualificação profissional. Corroborando a percepção de que, mesmo sem obter emprego, parte significativa dos egressos aprovou os cursos, bem como seus efeitos sobre a empregabilidade, é digno de nota o fato dos egressos que perderam o emprego após a participação no PEQ, avaliarem positivamente a política. A passagem seguinte sintetiza a avaliação feita pelos indivíduos que se encontravam nesta condição quando da realização da pesquisa:

"Ocupados que ficaram sem trabalho após o curso: Nesse estrato, 32,4\% declararam, como benefício, que o curso aumentou suas chances de conseguir trabalho; 24,6\% sentiram-se mais habilitados para conseguir um trabalho; $17,9 \%$ compreenderam que precisam estar mais atualizados e $12,3 \%$ tiveram mais informações sobre como conseguir emprego" (UNITRABALHO, 1998: 193).

Neste caso a política mostrou-se particularmente bem-sucedida na difusão de uma cultura que valoriza a empregabilidade mais do que o emprego propriamente dito. A idéia de que o emprego é uma "conquista individual", implícita no discurso sobre a empregabilidade, parece ser reforçada por aqueles que, apesar de terem perdido o trabalho após o curso, assumem como desafio pessoal a obtenção de uma nova ocupação, não responsabilizando a formação recebida por este insucesso. Ao contrário, é esta formação que, supostamente, aumentará suas chances de obter trabalho (apesar das "evidências" não terem apontado exatamente nesta direção).

Finalmente é interessante constatar que, mesmo entre os egressos inativos, isto é, os desocupados que não procuravam trabalho nem ao iniciar nem ao concluir o curso, o efeito deste sobre a empregabilidade percebida é visível, uma vez que os egressos deste grupo alegam que, em decorrência do curso:

"adquiriram mais conhecimentos (35\%), aumentaram as chances (17\%), sentem-se mais habilitados $(14 \%)$, sabem que precisam estar mais habilitados $(11 \%)$ e têm mais informações para conseguir trabalho (10\%)" (UNITRABALHO, 1998:198).

A participação no PEQ também contribuiu para a diminuição da taxa de inatividade, pois dentre aqueles que se declaravam inativos ao iniciar o curso (14\% do total de entrevistados), $47 \%$ decidiram procurar trabalho após a conclusão, sendo que $50 \%$ foram bem-sucedidos na procura. Neste grupo,

"cerca de $80 \%$ atribuem tal fato ao curso. Para estes, os principais benefícios que o curso trouxe para o novo trabalho foram: atualizar os conhecimentos, estar mais qualificado para A Dimensão Simbólica da Empregabilidade: Mercado, Políticas Públicas e Organização Social do Trabalho 
trabalhar, aumentar a renda pessoal e possibilitar o retorno ao mercado de trabalho $(68 \%$ desse subgrupo)" (UNITRABALHO, 1998:198).

É a partir destes resultados que podemos conceber as ações realizadas no âmbito do PLANFOR como etapa importante para a consolidação da versão que explica o desemprego a partir da categoria empregabilidade. Entende-se que a política, por pressupor um conjunto de atividades capazes de envolver um contingente expressivo de trabalhadores, criaria condições para a adesão destes aos pressupostos que a animam. Podemos pensar, novamente, se não estamos diante da "gestação de uma nova cultura do trabalho" (Silva, 1999) e se o PLANFOR não ocuparia papel de destaque neste processo.

\subsection{Motivos alegados pelos egressos para não encontrar trabalho}

No ano de 1997, quando perguntados sobre os motivos que os levaram a não obter trabalho na área do curso que realizaram, 24,6\% dos egressos afirmaram que há pouco trabalho nesta área, 13,39\% disseram que não existe trabalho onde moram, 12,03\% sentem-se incapacitados, $11,71 \%$ não tinham recursos para abrir negócio, 7,59\% não sabem procurar trabalho e 2,53\% não sabem como obter financiamento. (UNITRABALHO, 1997:53).

Estes resultados apontam, predominantemente, para problemas do mercado de trabalho (inexistência de oportunidades de trabalho) e deficiências do próprio curso, já que vários egressos não se consideraram capacitados para trabalhar na área de formação. Apesar de parte das respostas apontarem deficiências individuais, as principais dificuldades remetem a questões estruturais do mercado de trabalho e não a problemas pessoais do egresso. Nos anos seguintes - AVAL 1998 e 1999 - os resultados a esta mesma indagação estão sintetizados na tabela seguinte:

Tabela 1 - Dificuldades para obtenção de trabalho

\begin{tabular}{|l|c|c|}
\hline \multicolumn{1}{|c|}{ Dificuldades * } & $\mathbf{1 9 9 8}$ & $\mathbf{1 9 9 9}$ \\
\hline Não ter idade exigida & $21.6 \%$ & $10,91 \%$ \\
\hline Não ter escolaridade necessária & $5,7 \%$ & $5,70 \%$ \\
\hline Não ter oportunidade & $32,5 \%$ & $72,89 \%$ \\
\hline Não ter experiência anterior & $28,8 \%$ & $8,43 \%$ \\
\hline Não se sentir capacitado para trabalhar na área do curso & $28,0 \%$ & $22,36 \%$ \\
\hline Existir pouco trabalho na área do curso & $18,4 \%$ & $25,19 \%$ \\
\hline Falta de conhecimento sobre a atividade & $6,4 \%$ & - \\
\hline Não há trabalho relacionado ao curso no local de moradia & - & $21,82 \%$ \\
\hline
\end{tabular}

Fonte: UNITRABALHO, 1998 e 1999.

* A pergunta também permitia respostas múltiplas.

Como se pode constatar, nas pesquisas realizadas em 1998 e 1999 predominam explicações para o desemprego que ora remetem a problemas do mercado de trabalho (em 1999 este resultado é ainda mais marcante), ora a insuficiência na formação recebida. Esta deficiência é destacada pela equipe da UNITRABALHO tanto em 1998, quando afirma que

"nas suas avaliações, os alunos freqüentemente consideram os cursos como sendo muito curtos para o conteúdo proposto, e, ao mesmo tempo, constatam a grande heterogeneidade na composição das turmas, dificultando a aprendizagem" (UNITRABALHO, 1998: 197), quanto em 1999, ao considerar que "os alunos freqüentemente consideram os cursos como sendo muito curtos para o conteúdo proposto e com aulas práticas insuficientes" (UNITRABALHO, 1999: 57).

Com base nesses resultados pode-se afirmar que poucos são os egressos que assumem como responsabilidade sua o não ingresso no mercado de trabalho. Na pesquisa de egressos realizada em 2000, também são os obstáculos que remetem a questões estruturais do mercado 
de trabalho os mais apontados pelos entrevistados. A tabela seguinte, extraída de relatório, sintetiza os resultados:

Tabela 2 - Obstáculos para obtenção de trabalho

\begin{tabular}{|l|c|}
\hline \multicolumn{1}{|c|}{ Obstáculos * } & $\%$ \\
\hline Não se aplica. & $3,04 \%$ \\
\hline Desconhecimento de equipamentos e máquinas. & $3,18 \%$ \\
\hline Não tem material para trabalhar. & $4,98 \%$ \\
\hline Não tem habilidade exigida. & $7,61 \%$ \\
\hline Falta conhecimento sobre a atividade ou trabalho. & $7,61 \%$ \\
\hline Falta de escolaridade. & $8,99 \%$ \\
\hline Não-Resposta. & $14,11 \%$ \\
\hline Não tem idade exigida. & $19,23 \%$ \\
\hline As empresas não estão contratando trabalhadores. & $\mathbf{1 9 , 7 8 \%}$ \\
\hline Falta de experiência anterior. & $\mathbf{2 8 , 6 3 \%}$ \\
\hline Falta de oportunidade de trabalho/Não existe vaga. & $\mathbf{4 7 , 1 6 \%}$ \\
\hline
\end{tabular}

Fonte: UNITRABALHO, 1998 e 1999.

* A pergunta permitia respostas múltiplas (até três opções).

Como podemos constatar, as causas estruturais do desemprego - falta de vagas/trabalho - aparecem em $67 \%$ das respostas. O elevado percentual de jovens egressos (40,6\% com menos de 25 anos) explicaria a incidência elevada de respostas indicando falta de experiência anterior $(28,63 \%)$ e idade exigida $(19,23 \%)$. As opções que sugerem mais diretamente a responsabilidade do egresso pela dificuldade em obter trabalho (falta de habilidade/escolaridade etc) não totalizam mais de $33 \%$.

Resultados semelhantes a estes aparecem na pesquisa realizada em 2001; novamente são os condicionantes estruturais os principais causadores do desemprego. A tabela seguinte expõe as principais dificuldades apontadas pelos egressos:

Tabela 3 - Dificuldades para obtenção de trabalho

\begin{tabular}{|l|c|}
\hline \multicolumn{1}{|c|}{ Dificuldades * } & \% \\
\hline Falta de oportunidade de trabalho/Não existe vaga. & $\mathbf{6 7 , 0 \%}$ \\
\hline Não sabe usar equipamentos e máquinas & $3,4 \%$ \\
\hline Não tem material para trabalhar. & $2,0 \%$ \\
\hline Não tem habilidade exigida. & $11,9 \%$ \\
\hline Falta de experiência anterior. & $53,7 \%$ \\
\hline Falta de escolaridade. & $22,9 \%$ \\
\hline Falta de recursos para montar negócio. & $5,5 \%$ \\
\hline Não tem idade exigida. & $16,8 \%$ \\
\hline Discriminação social, racial ou de gênero. & $1,8 \%$ \\
\hline
\end{tabular}

Fonte: FUJB-LABTec/UFRJ, 2002:16.

* A pergunta permitia respostas múltiplas.

Também neste ano a falta de oportunidades de trabalho aparece com o maior percentual (67\%), sendo seguida pelas opções relacionadas à pouca idade dos egressos - falta de experiência e idade - dado que 40,4\% destes tinham menos de 25 anos. Novamente as opções que responsabilizam os egressos pelo desemprego, excetuando a que remete ao problema da baixa escolaridade - recebem menor atenção.

A Dimensão Simbólica da Empregabilidade: Mercado, Políticas Públicas e Organização Social do Trabalho 


\section{Considerações finais}

Buscando entender como mudanças no discurso acerca do trabalho vinculam-se a mudanças mais amplas de reorganização da produção capitalista, este artigo teve como objetivo discutir como o neologismo empregabilidade emerge como possibilidade conceitual de adequar no plano simbólico e, como decorrência, no plano objetivo, os trabalhadores a uma nova organização do trabalho.

Os resultados das avaliações dos PEQs-RJ nos levam a fazer ressalvas à argumentação de que o discurso sobre a empregabilidade vem propiciando a mudança de atitude e mentalidade dos trabalhadores, adequando-os às novas condições do mercado de trabalho. Apesar de estar em curso um processo de ressignificação da noção de emprego e das condições de inserção no mercado de trabalho - resumidas na categoria empregabilidade esta ainda não pode ser considerada efetiva.

Se por um lado os resultados da pesquisa inicialmente apresentados sugerem a adesão dos egressos aos pressupostos que orientam o PLANFOR, por outro, os resultados apresentados no final da última seção relativizam esta primeira percepção. Apesar dos egressos parecerem valorizar a conquista da empregabilidade ao aprovarem a qualificação recebida, estes mesmos indivíduos, quando questionados sobre os motivos que os levam ao desemprego, apontam para causas estruturais (poucas oportunidades, mercado de trabalho em crise) deixando em segundo plano, explicações que poderiam indicar sua responsabilidade por esta situação.

Neste sentido pode-se dizer que o discurso da empregabilidade - fundamentado na individualização do problema do desemprego - foi incorporado pelos egressos dos PEQs, mas esta incorporação foi parcial, incompleta. Não obstante os relatos de que se sentiam mais "empregáveis" após os cursos, entende-se que os egressos não aderiram integralmente à ordem cognitiva subjacente à categoria empregabilidade, posto que não assumiram o desemprego como responsabilidade individual.

Um possível entendimento acerca desta situação pode ser o de que a dimensão simbólica, no sentido bourdiano do termo, ainda encontra-se em formação, sendo a dimensão objetiva - proveniente dos efeitos do processo de precarização das relações de trabalho ainda muito presente. Neste sentido, a resistência dos trabalhadores em assumir a responsabilidade por sua empregabilidade pode ser vista como um fato positivo.

Um segundo entendimento acerca dos resultados encontrados - complementar ao primeiro - diz respeito à força do discurso hegemônico da empregabilidade. Nesse sentido, este discurso depara-se com o significativo desafio de realizar as promessas oferecidas pelas práticas de educação profissional e qualificação para o trabalho em uma realidade constituída por condições de reprodução da sociedade vinculadas a processos de reestruturação produtiva e políticas de flexibilização laboral que geram desemprego.

Como já enfatizadas anteriormente, estas talvez sejam promessas difíceis de serem realizadas uma vez que são fundamentadas (e impostas) por uma forma específica de entendimento acerca do mundo do trabalho ideal contemporâneo (1) conveniente aos grupos sociais dominantes em nossa sociedade; (2) que transfere para os trabalhadores grande parcela do ônus da reestruturação produtiva; (3) que não prioriza a ação do Estado como promotor de políticas capazes de incrementar a criação de empregos; e (4) que desdobra-se no esvaziamento das condições de negociações sindicais e políticas dos trabalhadores.

Enfim, assumindo que o discurso produz visões de mundo hegemônicas que enquadram, moldam e constituem as relações entre os atores sociais (muitas vezes sem nem mesmo aparentar isso para os próprios atores), buscar superar esse desafio e melhor compreender a temática da empregabilidade adquire relevância. Ao assim proceder talvez seja Lemos, A. H. C.; Costa, A. M. 
possível transcender a instrumentalização da educação - concebida a partir das necessidades da esfera da produção - deixando de corroborar o discurso que atrela o sucesso ou o fracasso no rumo profissional à simples expressão dos talentos, atributos e escolhas individuais. E em particular no contexto atual, onde processos de desregulamentações e reestruturações produtivas redefinem as relações entre capital e trabalho considerando a dimensão humana apenas como mais um componente de produção e reprodução econômica.

\section{Referências}

AKTOUF, Omar. Pós-Globalização, Administração e Racionalidade Econômica: a Síndrome do Avestruz. São Paulo: Atlas, 2004.

AMADEO, Edward. Dez Pontos sobre a Situação Recente do Mercado de Trabalho. Brasília: Ministério do Trabalho, agosto, (Notas sobre o Mercado de Trabalho, número 5). 1998.

AMADEO, Edward. Desemprego, salários e preços: um estudo comparativo de Keynes e o pensamento macroeconômico da década de 70. Rio de Janeiro: BNDES. 1987.

ALENCAR, Mônica Maria Torres; GRANEMANN, Sara. Ofensiva do Capital e Novas Determinações do Trabalho Profissional. Revista Katálysis, Florianópolis, v.12, n.2, p.161169, jul/dez, 2009.

ALVES, Edgard Luiz Gutierrez e VIEIRA, Carlos Alberto dos Santos. Qualificação profissional: uma Proposta de Política Pública. In: ALVES, Edgard Luiz Gutierrez (org.). Modernização Produtiva e Relações de Trabalho no Brasil: perspectivas de políticas públicas. Petrópolis, RJ: Vozes; Brasília, DF: IPEA, 1997.

ALVES, Giovanni. Trabalho e Reestruturação Produtiva no Brasil Neoliberal: Precarização do Trabalho e Redundância Salarial. Revista Katálysis, Florianópolis, v.12, n.2, p.188-197, $\mathrm{jul} / \mathrm{dez}, 2009$.

ANTUNES, Ricardo. O caracol e sua concha: ensaios sobre a nova morfologia do trabalho. São Paulo, Boitempo, 2005.

ANTUNES, Ricardo. Os sentidos do trabalho: ensaio sobre a afirmação e a negação do trabalho. São Paulo, Boitempo, 1999.

ANTUNES, Ricardo. A crise, o desemprego e alguns desafios atuais. Serviço Social e Sociedade, São Paulo, n.104, p 637-649, out/dez 2010.

BALTAR, Paulo e MATTOSO, Jorge. Estrutura Econômica e emprego no Brasil: a experiência recente. In: VELLOSO, João Paulo dos Reis (coord.). Brasil: Desafios de um país em transformação - Forum Nacional. Rio de Janeiro: José Olympio, 1997.

BARROS, Ricardo Paes, COSSIO, Maurício Blanco e TELES, Jorge Luiz. A eficácia das políticas de trabalho e renda no combate à pobreza. IN: VELLOSO, João Paulo dos Reis (coord.). Soluções para a questão do emprego - Forum Nacional. Rio de Janeiro: José Olympio, 2001. 
BOLtANSKI, Louis; CHIAPEllo, Eve. O Novo Espírito do Capitalismo. São Paulo: Martins Fontes, 2009.

BOTELHO, Maurilio Lima. Forma e ethos do trabalho: ensaio sobre a reformulação de uma ideologia. Revista Katálysis, Florianópolis, v.12, n.2, p.198-206, jul/dez, 2009.

BOURDIEU, Pierre. O Poder Simbólico, Rio de Janeiro: Bertrand Brasil, 1998.

BRANDÃO, Maria da Graça Pinto. Plano Nacional de Qualificação do Trabalhador PLANFOR: acertos, limites e desafios vistos do extremo sul. São Paulo em Perspectiva, v.18, n.4, p.39-49, 2004.

BRAVERMAN, Harry. Trabalho e capital monopolista: a degradação do trabalho no século XX. Rio de Janeiro: Zahar, 1981.

BRIDGES, William. Mudanças nas relações de trabalho. São Paulo: Makron Books, 1995.

CARDOSO, Adalberto, CARUSO Luis Antonio e CASTRO, Nadya. Trajetórias ocupacionais, desemprego e empregabilidade. Há algo de novo na agenda dos estudos sociais do trabalho no Brasil. Contemporaneidade e Educação, Rio de Janeiro: IEC, ano II, $\mathrm{n}^{\circ}$ 1: 723, 1997.

CARDOSO, Adalberto Moreira. Economia x Sociologia: eficiência ou democracia nas relações de trabalho? DADOS, Rio de Janeiro 43: 45-82, 2000.

CARRIERI, Alexandre e SARSUR, Amyra M. Percurso semântico do tema Empregabilidade: (re) construção de parte da história de uma empresa de telefonia. RAC-Revista de Administração Contemporânea, v.8. n.1, jan./mar. p.129-150, 2004.

CARRIERI, Alexandre de P.; SARAIVA, Luiz Alex S. Simbolismo Organizacional no Brasil. São Paulo: Atlas, 2007.

CARRIERI, Alexandre de P.; CAVEDON, Neusa; SILVA, Alfredo R. L. (Coord) Cultura nas Organizações: Uma Abordagem Contemporânea. Curitiba: Juruá: 2008.

CASTEL, Robert. As metamorfoses da questão social: uma crônica do salariado. Petrópolis: Vozes, 1998.

CHOMSKY, Noam. O Lucro ou as Pessoas. São Paulo: Bertrand Brasil, 2002.

COLBARI, Antônia de Lourdes. A retórica do empreendedorismo e a formação para o trabalho na sociedade brasileira. SINAIS - Revista Eletrônica, 1 (1), p.75-111, 2007.

COUTINHO, Luciano. A especialização regressiva: um balanço do desempenho industrial pós-estabilização. In: VELLOSO, João Paulo dos Reis (coord.). Brasil: desafios de um país em transformação. Rio de Janeiro: José Olympio, 1997.

FOUCAULT, Michel. A Ordem do Discurso. São Paulo: Loyola, 15ª Ed. 2007. 
FUJB/ FUJB-LABTec; UFRJ. Relatório Final de Avaliação Externa do Plano Estadual de Qualificação no Estado do Rio de Janeiro. Rio de Janeiro, 2001.

FUJB-LABTec; UFRJ. Avaliação Plurianual do Plano Estadual de Qualificação no Estado do Rio de Janeiro 1996-2001. Rio de Janeiro, 2002.

HARVEY, David. Condição Pós-Moderna. 19ª ed. São Paulo: Loyola, 2010.

HELAL, Diogo Henrique; NEVES, Jorge Alexandre e FERNANDES, Danielle Cireno. Empregabilidade gerencial no Brasil. RAC-Revista de Administração Contemporânea Eletrônica, v1.,n.2, maio/ago. p 1-19, 2007.

HELAL, Diogo Henrique e ROCHA, Maíra, O discurso da empregabilidade: o que pensam a academia e o mundo empresarial. Cadernos Ebape.BR, v.9,n.1, p.139-154, março, 2011.

LEMOS, Ana Heloísa. Qualificação profissional e desemprego: a construção social de um problema. Tese de Doutorado. Rio de Janeiro, IUPERJ, 2003.

LEMOS, Ana Heloisa C. e PINTO Mario Couto S. Empregabilidade dos administradores: quais os perfis demandados pelas empresas? Cadernos Ebape.BR, v.6,n.4, p.1-15, dez. 2008.

LEMOS, Ana Heloísa Costa, RODRIGUEZ, Daniel Arbaiza, MONTEIRO, Vinicius, Carvalho. Empregabilidade e Sociedade Disciplinar: uma Análise do Discurso do Trabalho Contemporâneo à Luz de Categorias Foucaultianas. Organizações \& Sociedade (Impresso), v.18, p.567 - 584, 2011.

LOPES, Ana Luiza S. e SILVA, José Roberto G. Expectativas profissionais de terceirizados em TI, RAE-Revista de Administração de Empresas Eletrônica, v.8.,n.2, art. 7, jul./dez. 2009.

MACHADO, Lucilia. Educação Básica, Empregabilidade e Competência. Trabalho e Educação, Belo Horizonte, n.3, jan./jul, 1998.

NÁDER, Fernanda Milne-Jones e OLIVEIRA Lucia Barbosa. Empregabilidade: Uma Análise Histórica e Crítica. In: ENCONTRO NACIONAL DE PÓS-GRADUAÇÃO EM ADMINISTRAÇÃO - EnANPAD, 31, 2007, Rio de Janeiro, RJ, Anais ... Rio de Janeiro: Anpad, 2007. CD-ROM.

SARSUR, Amyra M. Repensando a "Empregabilidade", a "Empresabilidade" e a "Nova" Gestão de Recursos Humanos: Um Estudo junto a Organizações e Profissionais em Minas Gerais. In: ENCONTRO NACIONAL DE PÓS-GRADUAÇÃO EM ADMINISTRAÇÃO - EnANPAD, 25, 2001, Campinas, SP, Anais ... São Paulo: Anpad, 2001. CD-ROM.

SILVA, Luís Antônio Machado. Trabalhadores do Brasil: Virem-se. Inteligência, ano I, n.5, dez-jan, p. 60-65, 1998.

MTE/SPPE. (2001), Guia do Planfor. Brasília, 2001. 
NERI Marcelo, CAMARGO José Márcio, REIS, Maurício Cortez. Emprego e produtividade no Brasil na década de 90. Rio de Janeiro: PUC, out. (Texto para Discussão, 405). 1999.

OFFE, Claus. Capitalismo Desorganizado. São Paulo: Editora Brasiliense, 1989.

PIORE, Michael. e SABEL, Charles. The Second Industrial Divide: Possibilities for Prosperty. New York: Basic Books, 1984.

POCHMANN, Márcio. O emprego na globalização. São Paulo: Boitempo Editorial, 2001a.

POCHMANN, Márcio. A década dos mitos. São Paulo: Editora Contemporânea., 2001b.

RAMOS, Lauro e REIS, José Guilherme Almeida. Emprego no Brasil nos anos 90. Rio de Janeiro: IPEA, março (Texto para Discussão, 468). 1997.

RIFKIN, Jeremy. The End of Work: the Decline of Global Labor Force and the PostMarket Era. New York:Tarcher, 1995.

RODRIGUES, José. (1997), "Da teoria do capital humano à empregabilidade: um ensaio sobre as crises do capital e a educação brasileira", In: Trabalho e Educação: Belo Horizonte, NETE/FAE/UFMG, n.2:215-230, ago./dez.

ROSA, Alexandre Reis e MOZAR, José de Brito. Ensaio sobre a violência simbólica nas organizações. Organizações \& Sociedade, v.16, n.51, 2009. pp 629-646.

SADER, Emir. Desequilíbrios Estruturais do Capitalismo Atual. Le Monde Diplomatic Brasil, ano II, nº14, setembro de 2008.

SANTOS, Boaventura de Souza. Produzir para viver: os caminhos da produção nãocapitalista. Rio de Janeiro: Record, 2002.

SARAIVA, Luiz Alex S.; GOMES, Lucilene Aparecida; COIMBRA, Emanuelle Reis; FERRERO, Aline de Moura. Significados do Trabalho para Trabalhadores Precarizados: Uma Análise de Desenhos. In: ENCONTRO DE GESTÃO DE PESSOAS E RELAÇÕES DE TRABALHO - EnGPR, 3, 2011, João Pessoa, PA, Anais ... João Pessoao: EnGPR, 2011. CD-ROM.

SCHULTZ, Theodore. O valor econômico da educação. Rio de Janeiro, Zahar, 1967.

SOARES, Rodrigo Reis; Gustavo GONZAGA. Determinação de salários no Brasil: dualidade ou não-linearidade no retorno à educação? Rio de Janeiro: IPEA, dez. (Texto para Discussão, 38). 1997.

SOUSA, Salviana de Maria Pastor Santos. A Questão da Descentralização Participativa na Gestão do PLANFOR: Qual Democracia? Revista Katálysis, v.10. n.2, p.256-264, julho/dez, 2007. 
TEIXEIRA, José Emídio e RIOS, Iaci. Empregabilidade e aprendizagem. Seminário Internacional Educação Profissional, Trabalho e Competências, Rio de Janeiro, nov. Anais. 1998.

UNITRABAlHO. Relatório Final de Avaliação Externa do Plano Estadual de Qualificação no Estado do Rio de Janeiro. Rio de Janeiro. 1997.

UNITRABALHO. Relatório Final de Avaliação Externa do Plano Estadual de Qualificação no Estado do Rio de Janeiro. Rio de Janeiro. 1998.

UNITRABALHO. Relatório Final de Avaliação Externa do Plano Estadual de Qualificação no Estado do Rio de Janeiro. Rio de Janeiro. 1999.

UNITRABAlHO. Relatório Final de Avaliação Externa do Plano Estadual de Qualificação no Estado do Rio de Janeiro. Rio de Janeiro. 2000.

WOOD Jr, Thomas. Organizações de Simbolismo Intensivo. RAE - Revista de Administração de Empresas, v.40, n.1, jan-mar 2000.

WOOD JR, Thomas.; DE PAULA, Ana Paula Paes de. Pop-Management. Anais do XXV ENANPAD, Campinas, 2001.

WOOD JR, Thomas.; DE PAULA, Ana Paula Paes de. A Midia Especializada e a Cultura do Management. Organizações \& Sociedade, 13(38), 91-105, 2006. 